Class Party and State Party: Comparing Republicanism in São Paulo and Rio Grande do Sul, 1873-1930

\section{Republicanismo Paulista e Republicanismo Gaúcho, entre o partido de classe e o partido de Estado: aproximações e distinções (1873-1930)}

\section{Rafael Augustus Sêga \\ Doutor em História pela Universidade Federal do Rio Grande do Sul (IFCH/UFRGS-Porto Alegre/ Brasil) e Professor de História no Departamento Acadêmico de Estudos Sociais da Universidade Tecnológica Federal do Paraná (UTFPR-Curitiba/Brasil) e-mail: rafasega@gmail.com}

\section{Renato Monseff Perissinotto \\ Doutor em Ciências Sociais pela Universidade Estadual de Campinas (IFCH/UNICAMP- Campinas/Brasil) e Professor de Ciência Política no Departamento de Ciências Sociais da Universidade Federal do Paraná (FFCL/UFPR- Curitiba/Brasil) e-mail: monseff@uol.com.br}

\section{Resumo}

Este artigo compara os "instrumentos políticos" utilizados pela alta burocracia paulista para impor sua política tributária e cafeeira ao "capital cafeeiro" com os "instrumentos políticos" utilizados por uma jovem pequena burguesia urbana gaúcha para impor uma reorganização do aparato estatal estadual nos moldes da "cientificidade" positivista frente aos antigos liberais da campanha (pampa), que dominaram, em grande parte, o poder político do Estado no período imperial.

\section{Abstract}

This article compares the "political instruments" used by São Paulo's high bureaucracy to impose its tax and coffee policies on "coffee capital" with the "political instruments" used by Rio Grande do Sul's new urban petite bourgeoisie to impose a political reorganization of the State apparatus inspired by the "scientific" positivism and against the interests of the ranching elites who had hitherto dominated the state.

Palavras-chave

Brasil Primeira República, coronelismo, História de São Paulo, História do Rio Grande do Sul, Partido Republicano Paulista, Partido Republicano Rio-Grandense

Keywords

Brazil's First Republic, coronelism, São Paulo History, Rio Grande do Sul History, São Paulo Republican Party, Rio Grande do Sul Republican Party 
1

OVE, Joseph. 0 Rio Grande do Sul como fator de instabilidade na República Velha. In: FAUSTO, Boris (org.). História geral da civilização brasileira. 4aed. São Paulo: Difel, tomo III, vol.01, 1985. p.99.

2

Para Nunes Leal, o "compromisso coronelista", durante o período em questão, é, em termos gerais, o "resultado da superposição de formas desenvolvidas do regime representativo a uma estrutura econômica e social inadequada" (página 20). Desse ponto de vista, a estrutura agrária brasileira, calcada no latifúndio e nas relacõos de dependência pessoal dos "camponeses" frente aos proprietários de terra, constitui-se na 'base material' de sustentação e continuidade do poder privado dos coronéis. Do coronel os "dependentes" recebem todo tipo de ajuda: financeira, médica, jurídica etc. Como consequência, essa dependência pessoal traduzse politicamente em fidelidade eleitoral. IN: LEAL Victor Nunes. Coronelismo, enxada e voto: 0 município e o regime representativo no Brasil. $3^{2}$ ed. São Paulo: Alfa - Omega, 1976.

3

0 termo "partido de classe" designa uma organização partidária voltada para a defesa, na luta política, dos interesses de uma classe determinada, às vezes explícita e diretamente, às vezes implícita e indiretamente. A nosso ver esse caráter da organização partidária pode ser comprovado por três critérios conjugados: a composição social de seus membros, sobretudo de seu órgão diretor; a natureza dos temas debatidos e rejeitados pelo partido e as soluções propostas e perseguidas pela organização. 0 termo "partido de Estado" (ou "partido da administração estatal") refere-se a uma organização partidária ostensivamente controlada pela burocracia estatal e colocada a serviço desta com vistas a regular o acesso aos cargos públicos, fortalecer os recursos organizacionais do Estado e reprimir as eventuais resistências à sua orientação política, inclusive aquelas oriundas dos grupos economicamente dominantes.
Considerações preliminares

0 estudo dos partidos políticos, no âmbito das Ciências Sociais, tem obtido destaque nos últimos anos, em razão da revalorização do Estado e das instituições políticas como objetos de análise. As abordagens que levam em conta o espaço político simplesmente como uma arena em que interesses sociais organizados se digladiam para viabilizar seus objetivos vêm sendo contraposta a outras em que os fatores político- institucionais aparecem como determinantes para o desenrolar dos eventos políticos e sociais. Por exemplo, estudos recentes vêm mostrando que o Estado nacional brasileiro esteve quase sempre longe de ser um mero instrumento nas mãos das classes dominantes locais, tanto no nivel federal como nos regionais.

São Paulo, como se sabe, foi o centro incontestável da economia exportadora durante a Primeira República e pode-se detectar um amplo processo de expansão e fortalecimento da burocracia estatal, cujo resultado foi ter propiciado uma crescente centralização do comando sobre as políticas cafeeira e tributária em mãos da alta cúpula burocrática. Já o Rio Grande do Sul constituiu um caso à parte no quadro brasileiro da Primeira República, tanto econômica como politicamente, pois esse Estado não voltou sua produção nem para exportação nem para mera subsistência, mas sim para o mercado interno nacional. Politicamente, a marca da política gaúcha foi o isolamento regional e a polarização entre dois núcleos partidários, com nítidas orientações ideológicas: positivismo versus liberalismo. ${ }^{1}$

0 objetivo deste artigo é comparar os "instrumentos políticos" utilizados pela alta burocracia paulista para impor ao "capital cafeeiro" as suas orientações na condução das políticas tributária e econômica com os "instrumentos políticos" utilizados por uma jovem pequena burguesia urbana gaúcha para impor a reorganização do aparato estatal frente aos antigos liberais da campanha. 0 tema geral deste artigo, portanto, abrange o complexo problema da relação entre o Estado e as classes economicamente dominantes.

No presente artigo, utilizaremos o conceito de "compromisso coronelista"2 proposto por Victor Nunes Leal. A partir desse conceito, pretendemos apresentar algumas proposições gerais acerca da construção e do fortalecimento de dois aparatos estatais regionais. A nossa hipótese é que, no caso paulista, o Partido Republicano Paulista (PRP) deixou, pouco a pouco, de ser um "partido de classe" para transformar-se num "partido de Estado"3 a serviço da burocracia estatal e do fortalecimento do aparelho de Estado; no caso gaúcho, essa transição também é perceptível, ainda que menos ostensiva do que em São Paulo. Ao contrário das interpretações tradicionais sobre a primeira república, defendemos que as instituições políticas têm certa autonomia frente às classes economicamente dominantes; para exemplificar isso, analisaremos a autonomia de dois partidos regionais (PRP e PRR) a partir do conceito de compromisso coronelista; a nosso ver, essa análise se justifica por São Paulo possuir a classe dominante mais poderosa do país à época e pelo fato do Rio Grande do Sul apresentar um desenvolvimento sui generis no modelo agrário-exportador do período em razão do modelo castilhista-borgista. Os partidos em tela são emblemáticos na medida em que se tornaram autônomos por motivos regionais peculiares, mas complementares no nível nacional. 
4

ZIMMERMANN, Maria Emília M. O PRP e os fazendeiros de café. Campinas: Editora da Unicamp, 1986. p.17.

5

Ibidem, p.38

6

CASALECCHI, José Ênio. O Partido Republicano paulista. São Paulo: Brasiliense, 1987. p.50.

7 ZIMMERMANN, Maria Emilia M. Op. Cit., p 25.

CASALECCHI, José Ênio. Op. Cit., p.54.

9

HOLANDA, Sérgio Buarque de. "São Paulo". In: _. (org.). História geral da civilização brasileira. Vol. 02. Tomo II. São Paulo: Difel, 1985. p.466.

10

CARVALHO, José Murilo. A construção da ordem: a elite política imperial. Brasilia: Editora da UNB, 1980. p.162.
0 Republicanismo Paulista (1873-1930)

Uma análise do PRP requer uma divisão deste partido em duas fases. Uma primeira, entre 1873 e 1889, e uma segunda abrangendo o período de 1898 a 1930. Os anos intermediários, de 1890 a 1897, foram marcados por grande instabilidade política. Só a partir de 1898 é que a "política dos governadores" trouxe a conhecida regularidade da vida política daquele período. Com base na literatura sobre o partido em questão, acreditamos poder dizer que este era, na primeira fase (1873 a 1889), um partido de classe, para, em seguida (1898 a 1930), em grande parte devido às regras impostas pela "política dos governadores", metamorfosear-se num "partido da administração".

Pensamos que o Partido Republicano Paulista, no período que vai de 1870 a 1889, era claramente um partido de classe. No entanto, não era o partido do conjunto da classe dominante paulista, mas sim apenas de um setor seu, qual seja, os "fazendeiros do Oeste paulista", e foi essa representatividade de classe que conferiu ao PRP a forte coesão tão enfatizada pela bibliografia como um traço característico da organização no período em questão. ${ }^{4}$

Assim, se olharmos a lista dos republicanos presentes no Primeiro Congresso do PRP, veremos que na sua quase totalidade eram oriundos daquela classe, inclusive os seus membros de atuação mais destacada, como Campos Salles, Prudente de Moraes, Martinho Prado Júnior e Moraes Barros. ${ }^{5}$ Segundo Casalecchi, a "vanguarda" do movimento republicano em São Paulo formava-se de "lavradores e capitalistas". Todos os encontros do partido, de 1874 a 1889, a começar pela convenção fundadora da organização, realizada em Itu, mantiveram "a mesma característica quanto a sua composição social".6 Ora, essa representatividade de classe esteve presente nos temas privilegiados pelo partido. Foi ela que fez do "federalismo" e da "reorganização do mercado de trabalho" os temas-chave daquela organização nos anos anteriores à proclamação da República ${ }^{7}$ A luta pela federação, de fato, foi o grande tema político do movimento republicano em São Paulo. Na verdade, ela transformou-se no objetivo que conferiu ao republicanismo paulista unidade e vigor. Isso só foi possivel, como nota Casalecchi, graças ao desenvolvimento material da província de São Paulo. A conjugação entre expansão econômica e centralismo monárquico fez da luta pela autonomia provincial o traço caracteristico do PRP. ${ }^{8}$

Se for certo que esse "impeto regionalista" dos "paulistas" vinha de longe, como nota Sérgio Buarque de Holanda ${ }^{9}$, não é menos certo que ele tenha se acentuado em função daquela conjugação. Aos olhos dos promotores da expansão cafeeira paulista, o Estado monárquico era um obstáculo a ser derrotado, pelo menos no seu aspecto centralizador. Quando a Monarquia mostrou-se intransigente quanto a este ponto, antigos adeptos começaram a retirar o seu apoio à Coroa. Para o capital cafeeiro, a federação seria a forma de romper as amarras monárquicas. Segundo José Murilo de Carvalho, a principal preocupação dos republicanos paulistas não era o governo representativo ou os direitos individuais, mas a autonomia estadual. "Eles pediam [...]", escreve Carvalho, "o governo a serviço de seus interesses. $E$ isto seria melhor conseguido através do fortalecimento e do controle pleno do governo estadual". ${ }^{10}$ Desse ponto de vista, uma das grandes vantagens da federação, por exemplo, seria conferir aos novos administradores da província autônoma o poder 
11

Apud BARRIGUELLI, José Cláudio (org.). 0 pensamento político da classe dominante paulista (1873-1928). São Carlos: UFSCAR /Arquivo de História Contemporânea, 1986. p. 20-21.

12

Boehrer mostra que o PRP era o partido mais bem organizado do movimento republicano. Já no período monárquico assumiu uma forma partidária, criando uma comissão permanente responsável pelos assuntos partidários, realizando convenções regulares, com ampla participação de delegados municipais. Tratava-se, pois, de um partido "rígido em disciplina, forte unidade, mas nunca idealista", baseado numa "rígida organização e centralização". IN: BOEHRER, George C. A. Da Monarquia à República: história do Partido Republicano do Brasil (1870-1889). Rio de Janeiro: Ministério da Educação e Cultura, 1954. p.119.

13

Registre-se que dos doze presidentes estaduais indicados pelo PRP durante a Primeira República, dez foram eleitos com $100 \%$ dos votos e os outros dois com "apenas" 98\% e 99\%. Cf. CASALECCHI, José Ênio. Op. Cit., p.271.

14

Ibidem, p.238. de suprimir o imposto de exportação sobre o café, seguindo, assim, um sistema vigente em vários paises, segundo o qual "nem uma taxa, nem um direito pode ser lançado sobre a exportação". Este seria o sistema que "mais se adaptaria à índole e às tendências do Partido Republicano"." Portanto, o federalismo era um objetivo político plenamente coerente com os interesses econômicos do capital cafeeiro, pelo menos na forma em que seus membros vislumbravam o seu funcionamento futuro. Pela sua composição social (grandes fazendeiros do Oeste paulista, inclusive seus líderes de maior destaque), pelos temas que dominavam a sua agenda de discussão (centralização monárquica e crise do trabalho), pelas soluções apontadas (federação e imigração, ao invés de democracia e abolição da escravidão), o PRP apresentava-se, entre 1873 e 1889, como uma organização partidária de classe. É esse seu caráter classista, consolidado em torno de objetivos claramente delineados, que garantiu ao partido ampla organização e coesão. ${ }^{12}$ Essa coesão não implicou, evidentemente, na ausência absoluta de conflitos no seu interior.

As mudanças institucionais ocorridas tiveram efeitos importantes sobre o PRP, que alteraram a sua natureza inicial e, por conseguinte, a sua relação com a classe que lhe deu origem. Dessa forma, a "política dos governadores", funcionando com base no "compromisso coronelista", teve, em nivel regional, uma consequência imediata: a consolidação das situações políticas estaduais. Essa consolidação gerou, devido ao próprio funcionamento daquele sistema, um monopólio da vida política estadual pelos partidos governistas, que, por sua vez, foi acompanhado por uma impossibilidade institucional de se praticar a oposição política. Em São Paulo, como se sabe, a organização que exerceu esse monopólio foi o PRP. ${ }^{13}$

Como resultado desse domínio absoluto propiciado pela "política dos governadores" e pelo "compromisso coronelista", o partido veio a ser uma organização continuamente próxima da administração estatal na medida em que se transformou em via obrigatória de acesso ao Estado em todas as suas dimensões, seja para a obtenção de cargos no funcionalismo público, seja para se ter acesso aos cargos eletivos, da vereança ao Executivo estadual.

Exatamente por causa dessa íntima relação com os negócios do Estado e com a burocracia é que, para galgar postos no partido e, por consequência, na política estadual, "não ser [ia] secundária a experiência acumulada nas longas carreiras, principiadas nos cargos burocráticos e judiciários exigidos pela urbanização do interior.". ${ }^{14}$ Era preciso agora possuir um saber exigido pela burocratização do Judiciário, da Força Pública, da Polícia Civil, dos "órgãos fazendários" etc., saber necessário, portanto, à nova maneira de se exercer as funções estatais instituída com 0 advento da República. Assim, ao lado da homogeneidade educacional, das relações de parentesco e da origem econômica, lembradas por Casalecchi, também a experiência dos indivíduos nas tarefas do Estado será fator importante para se ter acesso à "elite política" paulista. É lícito supor que o exercício dessas funções e a necessidade de lidar com os mais variados problemas a partir de uma ótica estatal serviram para "ressocializar" os membros dessa elite, atenuando o peso de sua origem de classe como fator explicativo de suas decisões.

0 monopólio político e a proximidade do PRP com a burocracia regional permitiram uma "continuidade administrativa" da qual os membros do partido gostavam de se vangloriar. Washington Luiz, por exemplo, na sua plataforma de candidato a presidente de São Paulo, 
DEBES, Célio. Júlio Prestes e a Primeira República. São Paulo: IMESP/DAESP, 1982. p.191.

CASALECCHI, José Ênio. Op. Cit., p.852-883.

17

Para informações mais detalhadas acerca desse processo de centralização interna do PRP, ver CASALECCHI, José Ênio. Op. Cit., p.189-202. Ver também: CARONE, Edgar e JUNQUEIRA, Maria Sílvia A. "Atas do Partido Republicano Paulista". Estudos Históricos, Marília, n.11, p.135-223, 1972, em especial as atas do partido de $07 / 11 / 1903,01 / 06 / 1904,01 / 10 / 1906$, 21/11/1913, 11/09/1919 e 01/02/1923, páginas 186, 188, 192-193, 200 e 210 respectivamente, que ilustram as mudanças apresentadas por Casalecchi nos procedimentos relativos à indicação dos candidatos a cargos eletivos e à própria Comissão Executiva.

18

Com o fim do primeiro periodo republicano, sob o domínio dos militares, e superadas as crises de transição do governo Prudente de Morais, chegara o momento de institucionalizar as relações entre poder central e governos estaduais. Até então, o país vinha sendo governado por oligarquias regionais solidamente enraizadas no coronelismo do interior, onde cada Estado, praticamente, constituia uma unidade autônoma. Empossado na presidência a 15 de novembro de 1898, Campos Sales deparou-se com a tarefa de dar uma forma política mais acabada a essa estrutura fragmentada. Denominada "política dos governadores", significou, na prática que o governo central deveria respeitar as decisões dos partidos que mantinham o poder em cada Estado, desde que estes elegessem bancadas no Congresso absolutamente fiéis ao presidente da República. 0 que permitia aos partidos estaduais assegurar antecipadamente a composição das bancadas era justamente 0 controle dos coronéis sobre seu eleitorado, os célebres "currais eleitorais". Neste esquema, o coronel controlava os votantes em sua área de influência. Ele obtinha votos para seu candidato em troca de presentes, como roupas e sapatos, ou de benefícios, como uma vaga num hospital ou um cargo público. Disponivel em: http://www. projetomemoria.art.br/RuiBarbosa/glossario/a/ politica-governadores.htm. Acessado em 27 de maio de 2008.

19

É nesse sentido que devemos entender as palavras de José Maria dos Santos ao lamentar as mudanças sofridas pelo PRP com o advento da República: "Não se diga que de tal mutação tenha ele mesmo [o PRP] sido o responsável. Ele foi vencido [...]". IN: SANTOS, José Maria dos. Bernardino de Campos e o Partido Republicano Paulista: subsidios para a história da República. Rio de Janeiro: José Olympio Editora, 1960. p.121.

20

WEBER, Max. Economía y sociedad: esbozo de sociología comprensiva. $7^{\mathrm{a}} \mathrm{ed}$. México: Fondo de Cultura Econômica, 1984. p.1078. referiu-se ao PRP exaltando o "espírito de continuidade administrativa" que contribuía para dar sequência às realizações dos governos perrepistas. ${ }^{15}$

Esta continuidade era, na verdade, o resultado necessário de um sistema político que matava no nascedouro qualquer possibilidade de alternância no poder, criando, assim, uma "burocracia política", no caso, uma "burocracia perrepista".

A partir da vitória republicana, transformado o PRP em organização do governo, o partido não poderia levar à cúpula do Estado indivíduos que ali atuassem como meros representantes de classe. Ao contrário, os seus membros deveriam estar preparados para tratar de problemas que ultrapassavam aquele estreito horizonte. À medida que as "questões administrativas" e as decisões que elas exigiam confrontavam-se com os interesses imediatos de classe, desagradando às suas associações, o PRP passou a distanciar-se cada vez mais dos anseios que lhe deram origem. Uma outra consequência desse monopólio, que transformou o PRP em "partido do governo", foi a crescente centralização da organização partidária. Nesse sentido, é interessante observar que o partido reproduziu na sua organização interna a mesma relação existente, fora dele, entre poder local e poder regional. Foi, assim, uma organização extremamente centralizada, detendo a sua Comissão Executiva todo o poder. A ela estavam totalmente subordinados os diretórios municipais. Segundo Casalecchi, o PRP, proclamada a República, reconhecia-se como um partido de governo que, enquanto tal, tinha "mais necessidade de uniformizar a ação coletiva". Para tanto, era preciso restringir "tanto quanto possível o círculo de deliberação". Este último seria, então, declaradamente limitado à Comissão Executiva, local de onde sairiam as indicações dos ocupantes dos cargos eletivos, no Legislativo e no Executivo. ${ }^{16}$ De acordo com essa lógica, aos diretórios municipais caberia tão somente referendar as decisões da Comissão e, num segundo momento, nem mesmo isso. ${ }^{17}$ Assim como os poderes municipais deveriam submeter-se docilmente às exigências do poder regional, os diretórios municipais do PRP achavam-se subordinados incondicionalmente à Comissão Executiva.

Portanto, a "política dos governadores"18 e o monopólio político por ela propiciado tiveram sobre o partido uma dupla consequência: de um lado, transformaram a agremiação em via exclusiva de acesso ao governo do Estado e à burocracia, estabelecendo entre o PRP e a administração estatal uma íntima relação; de outro, e consequentemente, aprofundaram a centralização do partido de modo a depositar na sua Comissão Executiva todo o poder de decisão acerca dos indicados para os cargos estatais, reprimindo, assim, a luta política em torno da questão. ${ }^{19}$

No entanto, dito desta forma, fica a impressão de que o PRP era um partido todo-poderoso ou, para usar a expressão weberiana, um partido "patrocinador de cargos", cujo único objetivo consistia simplesmente em conduzir os seus chefes por meio de eleições à direção máxima do Estado, para que esses, por sua vez, distribuíssem os cargos entre os seus correligionários..$^{20}$ Ao contrário do que pode parecer, a íntima aproximação entre governo e PRP depois do advento da República não redundou num controle do primeiro pelo segundo, mas exatamente no oposto. Com o passar do tempo, o Executivo estadual foi se fortalecendo cada vez mais, autonomizando-se em relação à Comissão Executiva do partido e submetendo-a aos seus desígnios. 0 PRP, enfraquecido frente ao Poder Executivo, foi, pouco a pouco, colocando-se em posição subordinada à alta cúpula burocrática 
21

Ibidem, p.1079 e p.1088.

22

CARONE, Edgar e JUNQUEIRA, Maria Sílvia A. Op. Cit., p.138.
MORAES, Plínio Guimarães. Condições de funcionamento do "bloco regional cafeeiro paulista": 1889-1919. Dissertação de mestrado. Universidade Estadual de Campinas, Instituto de Filosofia e Ciências Humanas, Campinas, 1987. p.69. do aparelho estatal, sediada naquele Poder, servindo-Ihe de instrumento de represália política aos que se arriscavam na oposição. Assim, o partido era "forte" na medida em que derivava a sua força do Estado, impunha rígida disciplina aos seus militantes e deixava de ser um mero instrumento de classe; era "fraco", porém, exatamente por estar inteiramente subordinado à alta cúpula burocrática sediada no Executivo.

Note-se, ainda, que o Legislativo paulista foi inteiramente esvaziado de poder durante o período, em função dos próprios princípios da "política dos governadores". Dessa maneira, não havia para o partido um espaço autônomo de atuação, que lhe pudesse garantir uma certa independência frente ao Executivo. De acordo com Weber, em Estados onde os parlamentos são fracos ou inexistentes, os partidos perdem a capacidade de comandar a distribuição de cargos e colocam-se em posição subalterna frente à "burocracia dominante".21 Foi o caso do PRP, que, subordinado à burocracia, não pôde instituir em São Paulo uma administração de "puros diletantes", recrutados exclusivamente pelos critérios das relações pessoais, como seria de se esperar caso fosse um mero partido "patrocinador de cargos", à moda dos partidos americanos. Assim, segundo Carone e Junqueira, embora a Comissão Executiva do PRP fosse um órgão poderoso dentro do partido, capaz de controlar os diretórios municipais, selecionando os candidatos a serem apresentados aos cargos públicos, funcionando, portanto, como órgão intermediário entre o Executivo e as reivindicações locais, ela não era, contudo, detentora de todo o poder, estando, ao contrário, submetida ao chefe do Executivo. Portanto, ainda de acordo com esses autores, o "partido se confunde com o Estado", mas, certamente, em detrimento de sua autonomia. Ou seja, "o poder mestre é o Executivo".22

0 crescente e constante fortalecimento do Executivo estadual e a subordinação do partido à sua orientação fez crescer as dissidências no interior do PRP. Assim, em oposição ao período anterior (1873 a 1889), em que a organização distinguia-se pela sua identidade de classe e pela coesão dai decorrente, o partido começou a sofrer, a partir do advento da República, processos de luta interna. Certamente, nenhuma delas o feriu de morte, mas, apesar disso, mostram-se importantes exatamente por revelarem aquilo que procuramos descrever rapidamente acima. Ou seja, pensamos que as dissidências no interior do partido podem ser interpretadas como uma reação da sua subordinação às vontades do Executivo, servindo, assim, de mais um indício do fato de que o PRP deixou de ser um partido de classe, no sentido estrito, para se transformar num "partido do Estado", isto é, de uma administração que, por várias razões, não era um mero instrumento a serviço dos interesses exportadores.

Como reforço dessa tese podemos citar o alerta de Campos Salles, Presidente da República, ao então dissidente Prudente de Moraes, em 1901. Este, descontente com a imposição do nome de Bernardino de Campos à sucessão estadual de Rodrigues Alves, procurou Salles para comunicar-Ihe que, daquele momento em diante, fazer-lhe-ia oposição. Campos Salles respondeu-Ihe o seguinte: "agradeço o aviso, mas você vai perder [...] por causa desta cadeira. Eu estou sentado nela; e quem nela se senta não pode ser vencido, dentro do estado".23 Ora, ao falar de si, Campos Salles estava também falando de Rodrigues Alves, então chefe do Executivo paulista, cuja cadeira tinha os mesmos dons daquela em que se sentava o Presidente da República. Dessa forma, como lembra Love, a dissidência de 1901 não se pautava por uma mera oposição ao nome indicado, mas também ao modo 
Segundo CASALECCHI, a indicação de Bernardino de Campos para a sucessão de Rodrigues Alves na Presidência do estado, feita por Campos Salles, foi encarada como uma intromissão indevida, já que deveria ser uma prerrogativa da Comissão Executiva do PRP. Cf. CASALECCHI, José Ênio. Op. Cit., p.102. Ver também: LOVE, Joseph. São Paulo na federação brasileira, 1889-1937: a locomotiva. Rio de Janeiro: Paz e Terra, 1982. p.160.

CASALECCHI, José Ênio. Op. Cit., caps. 03 e 04 de indicação, isto é, à "política dos governadores", que dava ao Executivo o poder das graças e das desgraças sobre qualquer indivíduo com pretensões políticas. ${ }^{24}$ Todos os outros conflitos políticos no interior do PRP estão, de uma ou outra maneira, vinculados a uma reação ao poder sufocante exercido pelo Presidente do estado sobre apolítica, em geral, e sobre o partido, em particular. Porém, os opositores foram sistematicamente derrotados.

Se analisarmos todas as dissidências por que passou o PRP, veremos que apenas duas delas (a de 1898, que gerou o efêmero Partido da Lavoura, e a de 1902, que levou os fazendeiros a pegarem em armas contra o partido) tiveram forte motivação econômica, dada a conjugação entre a crise de preços do café e a política contracionista de Campos Salles, apoiada, em nível estadual, por Rodrigues Alves. As outras foram dissidências eminentemente políticas, como por exemplo as reações ao monopólio das indicações de candidatos ou à prática da "política dos governadores", que garantiam à orientação governista a tão auto-elogiada "continuidade administrativa". 25

Ao lado do "compromisso coronelista" e da "política dos governadores", que estabeleceram as condições políticas que viabilizaram o processo acima descrito, é preciso também reconhecer que uma explicação complementar para as transformações sofridas pelo PRP reside nos imperativos colocados por uma economia exportadora baseada em um só produto. A manutenção do aparelho estatal e da "autoridade política" da burocracia paulista eram altamente dependentes dos recursos gerados pelo café, arrecadados através do imposto sobre a exportação. Este fato, conjugado com o caráter altamente instável da economia cafeeira, incentivou os agentes estatais a aprofundarem os mecanismos de controle sobre ela e a centralizá-los num locus do Estado que fosse o mais fechado possivel às injunções políticas, no caso, a Secretaria da Fazenda. Ora, de nada adiantaria, de um lado, centralizar o comando dessa economia no Executivo e, de outro, manter independente o partido que controlava a vida política no estado, pois, dessa maneira, as disputas partidárias e os interesses corporativos que eventualmente se fizessem presentes no PRP poderiam ter influência direta nas questões relativas à política cafeeira. Manter um controle rígido sobre os órgãos de gestão da economia exportadora exigia enfraquecer o partido e submetê-lo às determinações do "poder mestre", isto é, o Executivo.

Portanto, pensamos que o PRP deslocou-se da condição de um "partido de classe" para um "partido do Estado" por uma dupla determinação. De um lado, a estreita dependência frente a uma economia altamente instável exigia a centralização dos seus instrumentos de gestão no Executivo e o enfraquecimento do partido frente a este Poder, afastando, dessa forma, qualquer interferência das dissidências na condução das políticas tributária e cafeeira; de outro lado, aquele deslocamento pode ser visto como um efeito próprio do (ou, ao menos, como algo possibilitado pelo) "regime político" que se instalou no Brasil com o advento da República, especialmente com a implantação da "política dos governadores", a partir de 1898. Como vimos, esse "regime político" suprimiu qualquer possibilidade de alternância no poder, condenou ao ostracismo qualquer oposição política e conferiu ao PRP o monopólio político em São Paulo. Isto levou a uma confusão entre partido e Estado, a uma aproximação íntima do PRP com as injunções da administração estatal, afastando-o das reivindicações imediatas da sua classe de origem. Tanto o primeiro como o segundo fator 
26

"Ora, ai está exatamente a definição do monopólio que, ilegal e inconstitucionalmente, pretende exercer através de todos os séculos porvindouros, o PRP. Esse partido constitui um grupo de pessoas que desejam a concentração em suas mãos, com exclusão de todas as mais, do comércio ou da indústria, consciente da exploração de rendosos cargos públicos, da representação e administração [...]. É esse partido um filho degenerado e espúrio do Partido Republicano da propaganda [...]. 0 atual PRP é 0 mais submisso dos lacaios para com os magnatas que estejam na chefia do Executivo, na União e no estado". Cf. "Monopólio monstruoso" de Mário Pinto Serva, Diário Nacional, 26/07/1927: 03. É preciso lembrar que a alta direção do Partido Democrático era formada, em grande parte, por nomes tradicionais do setor exportador cafeeiro. 0 presidente do partido era ninguém menos do que o grande magnata do café, Antônio Prado, fazendeiro, exportador, banqueiro, dono de ferrovias etc. Sobre o PD cf. PRADO, Maria Lígia Coelho. A democracia ilustrada: o Partido Democrático de São Paulo, 1926-1934. São Paulo: Ática, 1986; NOGUEIRA FILHO, Paulo. Ideais e lutas de um burguês progressista: 0 Partido Democrático e a revolução de 1930. 2 vols. $2^{a}$ ed. Rio de Janeiro: José Olympio Editora, 1965; e PERISSINOTTO, Renato M. Estado e capital cafeeiro: burocracia e interesse de classe na condução da política econômica (18891930). Tese de doutorado. Universidade Estadual de Campinas, Instituto de Filosofia e Ciências Humanas, Campinas, 1997, cap. IX.

27

E não só ela. 0 PRP foi também instrumento fundamental na imposição de todas as reformas burocratizantes do aparelho estatal, no Judiciário, na Policia Civil, na Força Pública e nos órgãos fazendários. Para este ponto, cf. Ibidem, cap. III.

28

PESAVENTO, Sandra J. História do Rio Grande do Sul. 9a ed. Porto Alegre: Mercado Aberto, 2002. p.39.

29

Segundo Newton Luis Garcia Carneiro, a "história política gaúcha no periodo imperial é a história da polarização entre os "federal-regionalistas" ligados ao Partido Liberal ("Iuzias", majoritários e hegemônicos) e os "centralistas-unitaristas" ligados ao Partido Conservador ("caramurus" ou depois "saquaremas" minoritários)". 0 Partido Liberal gaúcho originou-se de (e mais tarde derivou) várias organizações menores, mas não achamos que a pormenorização deva ser levada a cabo no presente texto. IN: CARNEIRO, Newton L. G. A identidade inacabada, o regionalismo político no Rio Grande do Sul. Porto Alegre: EDIPUCRS, 2000. p.123.

30

SÊGA, Rafael A. Tempos belicosos, a Revolução Federalista no Paraná e a rearticulação da vida político-administrativa do Estado (1889-1907). Curitiba: Aos Quatro Ventos/CEFET-PR, 2005. p.226. levaram a um enorme fortalecimento do Executivo, que pôde, assim, subjugar o partido às suas determinações.

Portanto, não é de se estranhar que, na década de 1920, um poderoso setor do capital cafeeiro, descontente com a ação do Executivo e de seu partido, tenha se deslocado para a oposição política, criando o Partido Democrático, na esperança de que este último viesse a ser o PRP dos velhos tempos. ${ }^{26}$ Ao dizermos isso, não estamos adotando aqui a posição, sugerida por alguns, de que o PRP teria se afastado dos interesses cafeeiros para se aproximar dos grupos industrialistas e outros setores alternativos. Esse tipo de afirmação parece-nos empiricamente incorreta. Se os industriais sempre apoiaram o PRP, não o fizeram porque o partido adotou uma postura industrialista, mas sim por não terem outra alternativa política senão dar apoio à agremiação que mantinha um controle permanente sobre os recursos governamentais. Para uma classe ainda pouco articulada, sem um projeto hegemônico próprio, incapaz de se constituir em força política autônoma e fustigada por uma oposição política xenófoba, posicionar-se contra o PRP seria cometer suicídio político. Além disso, a ninguém é dado ignorar o fato inegável de que a única "política econômica" (continuada e consequente) realmente existente no período foi a política cafeeira. Não se pode obscurecer o fato evidente de que a maior parte dos recursos estatais foram gastos com o objetivo de garantir a reprodução ampliada da economia exportadora. No entanto, essa identificação entre, de um lado, os interesses do Estado e do PRP e, de outro, os interesses mais gerais do setor exportador não esgota a relação entre ambos. Se o Estado promoveu a reprodução ampliada da economia cafeeira, o fez segundo um sentido específico, não redutível aos interesses imediatos da classe em questão, em alguns momentos até mesmo francamente contrários a eles, tanto a curto como a longo prazo. Nessas circunstâncias, o PRP foi um instrumento do Estado, e não da classe, utilizado pelo Executivo para vencer toda e qualquer oposição à forma pela qual a alta burocracia paulista conduzia a política econômica e tributária. ${ }^{27}$

\section{O Republicanismo Gaúcho (1845-1930)}

0 republicanismo gaúcho tem origens mais controversas do que o paulista e o maior símbolo disso é a proclamação da República Rio-Grandense em 11 de setembro de 1836 por Antônio de Sousa Neto (1801-1866), após a vitória dos insurretos farrapos em Seival. Entretanto, após a assinatura, em 1845, do Tratado de Paz de Ponche Verde, acordo pelo qual o Rio Grande do Sul voltou a integrar o Império do Brasil, a política gaúcha passou a seguir os ditames nacionais ${ }^{28}$.

A proliferação do ideário republicano do Manifesto de 1870 chegou ao Rio Grande do Sul com um certo atraso. Em verdade, a política sul-rio-grandense durante o período imperial era, majoritariamente, terreno do Partido Libera ${ }^{29}$ e os militantes republicanos precisavam engajar-se nessa agremiação para obter espaço na política local, como foi o caso de Ramiro Fortes de Barcelos (1851-1916), eleito para a Assembleia Provincial em 1877, sob a bandeira liberal. Todavia, em linhas gerais, o Partido Liberal gaúcho não defendia a causa republicana, ao contrário de algumas outras províncias, onde parte do republicanismo local nasceu, por vezes, de dissidências do Partido Liberal provincial, como foi o caso do Paraná, por exemplo. ${ }^{30}$

Diferentemente do republicanismo paulista, a configuração de um "partido de classe" no Rio Grande do Sul na segunda metade do século XIX 
31

CARNEIRO, Newton L. G. Op. Cit., p.122.

32

PICCOLO, Helga I. L. "O autoritarismo de Júlio de Castilhos e Getúlio Vargas: a 'gauchização' da política brasileira no pós-1930". In: TARGA, Luiz R. P. (org.). Breve inventário de temas do sul. Porto Alegre: UFRGS/FEE/UNIVATES, 1998. p.196.

33

Idem. "A política rio-grandense no Império". In: DACANAL, José H. e GONZAGA, Sergius. (orgs.). $R S$ : economia e política. Porto Alegre: Mercado Aberto, 1979. p.105.

34

Idem. "0 federalismo como projeto político no Rio Grande do Sul". In: TARGA, Luiz R. P.(org.). Op. Cit., p.280-282.

35

CARNEIRO, Newton L. G. Op. Cit., p.270.

36

PICCOLO, Helga I. L. A política rio-grandense no Império... Op. Cit., p.116.

37

CARNEIRO, Newton L. G. Op. Cit., p.197. perpassou necessariamente pelas hostes do Partido Liberal imperial. Nesse ponto, para consubstanciar esse entendimento, nos rendemos às considerações de Newton Carneiro de que o autonomismo da elite local gaúcha somado ao processo da construção do Estado Nacional brasileiro ganhou visibilidade através do discurso parlamentar do Partido Liberal, porta-voz das camadas dominantes regionais. ${ }^{31} \mathrm{~A}$ origem econômica dessas camadas dominantes estava ligada, grosso modo, à atividade pecuária da campanha. Dessa feita, parte do republicanismo gaúcho, como representação de classe dominante, se originou da camada mais progressista do Partido Liberal, geralmente oriunda dos estancieiros "letrados" ou absenteistas. Entrementes, o liberalismo professado no Rio Grande do Sul durante o período em tela deve ser entendido como uma doutrina política peculiar, conservadora e não democrática ${ }^{32}$, pois para Helga Piccolo ${ }^{33}$, as principais bandeiras dos liberais gaúchos eram a descentralização e o autogoverno. Destarte, os liberais da campanha alinhavam-se ao pensamento liberal clássico no tocante ao limite do controle do poder estatal sobre as liberdades individuais, posição política que acabou se fundindo com o ideário "federalista", na compreensão das limitações do poder central brasileiro sobre a província sul-rio-grandense. Aqui apelamos novamente à historiadora gaúcha quando ela afirma que "o federalismo gaúcho remete ao poder privado regional e a seus interesses no espaço fronteiriço [...] pois, os estancieiros do Rio Grande do Sul, como fração da classe dominante local, queriam o Estado Imperial como porta-voz e defensor de seus interesses, se estes interesses não eram atendidos apregoavam e difundiam ideias autonomistas". ${ }^{34}$ Como vimos, se para o capital cafeeiro paulista, a federação seria a forma de romper as amarras monárquicas, para o capital campeiro gaúcho, a mesma seria uma forma de pressão política. No tocante ao liberalismo, ele tinha reservas, pois quando a situação econômica apertava as frações de classe dominante campeiras demandavam intervenção do Estado para ajudar os estancieiros, mas na hora de praticar contrabando de charque na fronteira uruguaia eles queriam o aparato estatal há milhas de distância.

No tocante à hipótese de que o Partido Liberal constituiu-se o "partido de classe" no Rio Grande do Sul invocamos mais uma vez Newton Carneiro quando ele afirma que a "estrutura social rio-grandense conferiu ao liberalismo regional, no século XIX, predominância sob as demais estratégias de manutenção do poder". ${ }^{35}$

Entrementes, dois fatores contribuiram para o realinhamento político interno do Rio Grande do Sul em fins do século XIX; primeiro, a lei Saraiva, de 1881, que concedeu maiores direitos políticos aos brasileiros naturalizados e aos acatólicos, ou seja, a massa dos colonos imigrantes ${ }^{36}$; segundo, a abolição da escravidão, que converteu inúmeros conservadores em republicanos. ${ }^{37} 0$ Partido Liberal, como "partido de classe", não teve sensibilidade para incorporar esses atores políticos nas suas fileiras, o que acabou sendo feito pelo Partido Republicano Rio-Grandense, o PRR, que, a nosso ver, assumiria depois o papel de "partido de administração estatal" no Estado gaúcho.

0 PRR foi fundado por políticos gaúchos com intuito de fomentar o ideário republicano no Estado do Rio Grande do Sul e derivou do Clube Republicano de Porto Alegre que, em fevereiro de 1882, propôs uma convenção para eleição de uma comissão com poderes de organização de um partido republicano no Estado gaúcho. Participaram desse processo 
TRINDADE, Hélgio. "Aspectos políticos do sistema partidário republicano rio-grandense (1882-1937)". In: DACANAL, José H. e GONZAGA Sergius. (orgs.). Op. Cit., p.123

39

Por exemplo, dois dos maiores nomes do PRR, Júlio de Castilhos e Pinheiro Machado, eram oriundos da região de Cruz Alta. Sobre a "aristocracia" campeira, ver: BELL, Stephen. "Early Industrialization in the South Atlantic: Political Influences on the Charqueadas of Rio Grande do Sul before 1860." Journal of Historical Geography, vol.19, n.4, p.399-411, 1993.

40

SILVA, Jandira M. M. da et alii. Breve histórico da imprensa Sul-Rio-Grandense. Porto Alegre: CORAG, 1986. p.271.

SOARES, Mozart P. 0 positivismo no Brasil, 200 anos de Augusto Comte. Porto Alegre: UFRGS 1998. p. 143.

42

RODRÍGUEZ, Ricardo V. Castilhismo, uma filosofia da República. Brasilia: Senado Federal, 2000. p.74

43

"Castilhismo-borgismo" (FRANCO, Sérgio da C. Homens de letras e a política: a política riograndense ao tempo do castilhismo-borgismo. Métis, Caxias do Sul, vol.2, n. 4, 2003) é a expressão mais aceita para designar a corrente política levada a cabo pelo PRR no Rio Grande do Sul durante quase toda Primeira República, consolidada a partir da doutrina professada por Júlio de Castilhos e da prática política levada a cabo por Borges de Medeiros. Castilhos foi redator de "A Federação", deputado constituinte, presidente do Estado do Rio Grande do Sul e elaborador da Constituição do Estado gaúcho de 1891; já Borges manteve-se à frente do executivo gaúcho como presidente de 1898 a 1928, com interrupção entre 1909 a 1913 (gestão de Carlos Barbosa).

44

RECKZIEGEL, Ana Luiza S. A diplomacia marginal: vinculações políticas entre o Rio Grande do Sul e o Uruguai, 1893-1904. Passo Fundo: EDIUPF, 1999. p.23

45

LOVE, Joseph. "O Rio Grande do Sul como fator de instabilidade na República Velha"... Op. Cit., p.113. republicanos engajados das mais variadas camadas sociais, como Alcides de Mendonça Lima (1859-1935), Antônio Augusto Borges de Medeiros (1863-1961), Apolinário Porto Alegre (1844-1904), Carlos Barbosa Gonçalves (1851-1933), Demétrio Ribeiro (1850-1933), Ernesto Alves de Oliveira (1862-1891), Fernando Fernandes Abbott (1857-1924), Germano Hasslocher (1862-1911), João de Barros Cassal (1858-1903), João Cezimbra Jacques (1848-1922), Joaquim Francisco de Assis Brasil (1857-1938), Júlio Prates de Castilhos (1860-1903), Ramiro Fortes de Barcelos, Venâncio Aires (1841-1885), entre outros..$^{38}$ Os fundadores do PRR não pertenciam à tradicional elite campeira gaúcha, mas não eram pessoas das camadas subalternas. Muitos deles eram detentores de títulos acadêmicos e provinham, em boa parte, das regiões norte, missioneira e serrana do Estado, regiões de ocupação mais tardia e, portanto, de economia menos desenvolvida que a do charque. ${ }^{39}$ Os fundadores do PRR constituiam uma classe média com mais capital cultural que capital econômico.

0 primeiro congresso do PRR aconteceu em 1883, sob liderança de Júlio de Castilhos, que passou a organizar o periódico "A Federação", impresso que se tornaria porta-voz do PRR entre 1884 e 1937. "A Federação" sempre tentou articular a divulgação do positivismo com questões políticas regionais e nacionais, além de apresentar ocorrências policiais, classificados e reclames comerciais. ${ }^{40}$

Desde sua fundação, o PRR foi influenciado pela doutrina positivista de Augusto Comte, com ênfase na racionalidade e na "regeneração" da sociedade e, para tanto, apregoava que 0 aparato estatal deveria se colocar acima das classes sociais para gerenciar os conflitos inerentes do desenvolvimento capitalista, mas, no fundo, essa era a justificativa para a montagem de um projeto regional profundamente autoritário de modernização conservadora. ${ }^{41}$ Ricardo Vélez Rodríguez, em seu trabalho "Castilhismo, uma filosofia da República", mostra que o castilhismo original foi, essencialmente, uma adaptação promovida por Júlio de Castilho com o intento de substituir a noção do equilibrio de interesses do liberalismo pela ideia da moralização dos indivíduos através da tutela do Estado. ${ }^{42}$

Em 1889, com a proclamação da República, o PRR (representante, em boa parte, de uma pequena burguesia urbana da capital) tentou consolidar o domínio sobre o governo do Estado do Rio Grande do Sul, mas isso não se deu de forma pacífica, pois os antigos membros do Partido Liberal também almejavam o poder e organizaram o Partido Federalista. Esse confronto resultou na "Revolução Federalista", entre 1893 e 1895, um conflito extremamente violento, que terminou com a vitória das forças do PRR, consolidou o "castilhismo-borgismo"43 à frente do governo estadual gaúcho ${ }^{44} \mathrm{e}$ selou o fim da trajetória de transformação do Partido Liberal-Federalista de "partido de classe" em "partido de Estado".

Entrementes, nos primeiros anos da Primeira República, o PRR recebeu, principalmente, apoio militar do governo central brasileiro em função da mútua rejeição ao projeto político "federalista" (liberal) encetado por Gaspar Silveira Martins (1834-1901). Sobre esse assunto, Joseph Love ${ }^{45}$ em seu texto "0 Rio Grande do Sul como fator de instabilidade na República Velha" é muito enfático: "diversas razões havia para os laços íntimos entre o PRR e o exército federal com vistas à lealdade regional". Paralelo a isso, a luta regional pós-Revolução Federalista deu-se principalmente no campo das medidas econômicas, quer seja no tocante aos tributos (com vistas à atração de partes do empresariado), quer seja no tocante à 
47

PINTO, Celi R. Positivismo, um projeto político alternativo. Porto Alegre: L\&PM, 1986. p.13.

48

FÉLIX, Loiva O. Coronelismo, borgismo e cooptação política. $2^{\text {a }}$ ed. Porto Alegre: UFRGS, 1996. p.21.

49

PICCOLO, Helga I. L. "O autoritarismo de Júlio de Castilhos e Getúlio Vargas: a 'gauchização' da política brasileira no pós-1930". In: TARGA, Luiz R. P.(org.). Op. Cit., p.197.

50

FÉLIX, Loiva 0. Op. Cit., p.79. Talvez a maior contribuição metodológica desse trabalho de Loiva Otero Félix foi o de rebater a noção de "coronel burocrata" preconizada por Raymundo Faoro em "Os donos do poder". "O conceito de coronel burocrata encerra a ideia de uma liderança local, ungida por Borges de Medeiros para ocupar algum posto relativamente proeminente na burocracia estatal ou municipal, de forma a Ihe render obediência incondicional na definição dos rumos da política municipal; segundo os autores (tradicionais), nem sempre o coronel burocrata tinha posses e patrimônio destacado; o conceito de coronel burocrata tendeu a esvaziar o conteúdo coronelista das análises relativas à política gaúcha" (Apud AXT, Gunter. "Contribuições ao debate historiográfico concernente ao nexo entre Estado e sociedade para o Rio Grande do Sul castilhista-borgista." Métis História Cultura, Caxias do Sul, v.1, n.1, p.39-70, 2002, p.62).

51

AXT, Gunter."A emergência da liderança política de Getúlio Vargas no Rio Grande do Sul coronelista e o seu governo no Estado"In: et alii. (orgs.). Da vida para a história: reflexões sobre a era Vargas. Porto Alegre: Procuradoria Geral de Justiça \& Memorial do Ministério Público, 2005.

52

LOVE, Joseph. 0 regionalismo gaúcho e as origens da revolução de 1930. São Paulo: Perspectiva, 1975. p.223. regulamentação das relações de trabalho (com vistas à atração de partes do operariado), assim como um dos trunfos adicionais do PRR foi a ênfase à educação pública. ${ }^{46}$

A inserção do Rio Grande do Sul na "política dos governadores" não acarretou mudanças institucionais no PRR em sua "natureza de classe" como vimos no caso paulista. Em termos classistas, o PRR foi muito mais uma combinação de vários grupos do que predominância de um. Nesse ponto, Celi Regina Pinto afirma que o PRR "desenvolveu um projeto não-oligárquico e o positivismo, ao mesmo tempo em que deu subsídios para o partido criar um Estado autoritário, que Ihe garantiu a reprodução do poder, foi também a base doutrinária de um discurso que apresentava o partido acima de interesses particulares. ${ }^{47} \mathrm{~A}$ construção da imagem de Júlio de Castilhos como patriarca e mentor do republicanismo gaúcho foi, segundo Loiva Otero Félix, fruto da "necessidade histórica de uma minoria apresentar-se como maioria para legitimar e justificar uma identidade." ${ }^{48}$

Ora, se no caso paulista o poder legislativo foi esvaziado de poder durante o período em questão, como vimos anteriormente, no caso gaúcho não foi diferente. A Assembleia dos Representantes (legislativo estadual gaúcho à época) tinha suas prerrogativas bem cerceadas diante da hipertrofia do executivo e os trabalhos da mesma acabavam limitando-se a três reuniões anuais com o único intuito de votar o orçamento e verificar as contas do governo estadual. ${ }^{49} \mathrm{Em}$ termos nacionais, o Estado gaúcho teve um papel mediano na política inaugurada por Campos Sales, ao lado do Rio de Janeiro e Pernambuco, que buscavam ocupar espaços atuando individualmente ou em conjunto. Contudo, o "compromisso coronelista" adquiriu, nas terras gaúchas, uma feição diferente e nesse ponto, alinhamo-nos ao entendimento da historiadora Loiva Otero Félix de que o coronelismo gaúcho fundiu as instâncias públicas e privadas de maneira muito própria e que ele variava de acordo com divisão regional: Zona Sul (campanha), Zona Serrana, Zona Colonial e Zona Litorânea. Para ela, a diferença do coronelismo gaúcho com o praticado nos demais estados em que o mesmo era essencialmente situacionista é que no Rio Grande do Sul existia uma oposição forte e permanente e a opção foi uma espécie de "coronelismo de partido", entendido como uma execução das ordens do PRR por parte dos coronéis não por imposição política, mas por convicção partidária em manter de pé a estrutura política castilhista-borgista..$^{50}$

Todavia, o historiador gaúcho Gunter Axt ${ }^{51}$ em seu texto "A emergência da liderança política de Getúlio Vargas no Rio Grande do Sul coronelista e o seu governo no Estado", mostrou que o PRR não manteve um controle tão absoluto assim sobre a política gaúcha na Primeira República e que as disputas regionais demonstraram que o PRR, embora dominante, não foi tão hegemônico assim, sujeito a diversas crises internas e mesmo eleitorais. Exemplos deram-se em vários momentos: a morte de Júlio de Castilhos em 1903; a indicação do marechal Hermes da Fonseca (1855-1923) ao senado no lugar de Ramiro Barcellos, que acabou rumando para oposição em 1915 e, por fim, a Revolta Assista de 1923, quando Assis Brasil e seus correligionários insurgiram-se contra Borges, provocando uma guerra civil no Estado. A peleja só terminaria em dezembro de $1923 \mathrm{com}$ o "Tratado de Pedras Altas", que estabeleceu que Borges poderia permanecer até o final do mandato em 1928, mas com impedimento da reeleição. ${ }^{52}$

Com efeito, para consolidarmos o arrazoado da configuração de um "partido de Estado" no Rio Grande do Sul acreditamos, contudo, que 
Do guarani "ximango", ave falconiforme de rapina, comum no extremo sul do Brasil e que virou epíteto depreciativo dado pelos federalistas ("maragatos") aos governistas, membros do PRR (SÊGA, Rafael A. Op. Cit., p.98).

54

AXT, Gunter. Contribuições ao debate historiográfico... Op. Cit., p.58.

55

PESAVENTO, Sandra J. "República Velha gaúcha: Estado autoritário e economia". In: DACANAL, José H.; GONZAGA, Sergius. Op. Cit.,p.209.

56

FONT, Mauricio. Planters and the State: The Pursuit of Hegemony in São Paulo, Brazil: 1889-1930. Ph.D. Dissertation, University of Michigan, 1983.

57

Ibidem, p.342.

58

LOVE, Joseph. São Paulo na federação brasileira... Op. Cit., p.227, p.231 e p.165.

59

CASALECCHI, José Ênio. Op. Cit., p.185. o PRR transformou a agremiação em via principal de acesso ao governo do Estado e à burocracia a partir do pressuposto de que a vitória "chimanga"53 na Revolução Federalista acarretou um rearranjo do pacto oligárquico estadual, herdeiro do período imperial. Para subsidiarmos esse entendimento, cremos que a consolidação do Estado burocrático-burguês no Rio Grande do Sul castilhista-borgista deva ser entendida levando em conta três aspectos: primeiro, a motivação da elite dirigente em remodelar o aparato estatal em função da ampliação dos atores políticos; segundo, 0 intervencionismo (por meio de políticas públicas) como forma de entendimento da elite dirigente com as frações de classe dominante e terceiro, o "compromisso coronelista" como fator de tensão entre o aparato estatal estadual gaúcho, o poder privado regional e o poder público federal..$^{54}$ Para Sandra Pesavento, "a partir da vitória republicana, tem-se a implantação, no Rio Grande do Sul, de um esquema de dominação apoiado num partido altamente burocratizado, rigidamente disciplinado e com embasamento filosófico definido".55

\section{Conclusão}

À guisa de conclusão, parte da nossa preocupação foi problematizar as teses que qualificam o PRP como um "partido dos fazendeiros", considerando esta classe como a proprietária do Estado. Autores como José Ênio Casalecchi, Joseph Love e Mauricio Font ${ }^{56}$ já forneceram indícios que servem de subsídio a essa hipótese. Segundo este último, o desenvolvimento político de São Paulo permitiu a emergência de uma burocracia profissional que dividiu com o partido centralizado muitas de suas funções. ${ }^{57}$ Para Love, embora o PRP tivesse uma Comissão Executiva poderosa, por volta da década de 1920 grande parte de seu poder já havia sido absorvido pelo Executivo paulista. ${ }^{58}$ De acordo com Casalecchi, o partido estava enlaçado ao Estado e deste "emanava todo o oxigênio essencial para a sua sobrevivência".59 Por outro lado, outra parte da nossa preocupação foi mostrar que, no Rio Grande do Sul, a constituição classista do PRR foi heterogênea e a contraposição política ao Partido Liberal se deu pela defesa de novas propostas administrativas e pela incorporação de novos segmentos sociais, não só o estancieiro. Todavia, como no resto do país sob a égide da "política dos governadores", o sistema político do PRR continuou fechado e a participação da sociedade civil nas decisões continuou extremamente reduzida.

Se num primeiro momento (1873-98), o PRP pode ser identificado como um partido de classe, seja pela sua composição social, seja pelos temas que dominavam a sua agenda de discussão, no Rio Grande do Sul, esse tipo de agremiação começou se configurar com as disputas da Guerra dos Farrapos (1835) e se desenvolver e consolidar-se no decurso do Segundo Império (1840-89) por meio do Partido Liberal.

No caso paulista, num segundo momento, em especial depois da implementação da "política dos governadores" (1898 a 1930), cuja operacionalidade baseava-se no "compromisso coronelista", o PRP passou a ter uma relação tão íntima com a administração estatal que, paulatinamente, vai se "contaminando" pelas suas preocupações. Enquanto partido subordinado à burocracia, o PRP irá refletir as suas demandas e orientações em detrimento das de sua classe de origem. Por outro lado, a constituição de um "partido de Estado" no Rio Grande do Sul não nasceu de uma continuidade, mas de uma ruptura muito violenta, a Revolução Federalista, que 
forjou um "consenso" profundamente autoritário nesse Estado por quase quatro décadas.

Ao nosso ver, essas mudanças se deram, em parte, por força do regime político imposto pela República, em especial depois de 1898, com a implementação da "política dos governadores". Assim, defendemos que as mudanças ocorridas ao nível do "regime político" (modalidades de luta política e partidária) tiveram efeitos diretos sobre os partidos em questão e sobre as suas capacidades de representação dos interesses de classe. As práticas políticas tradicionais presentes na base do "compromisso coronelista" foram politicamente funcionais ao processo de construção de duas estruturas políticas crescentemente burocratizadas e centralizadas, ditas "modernas".

Por fim, acreditamos que a contribuição maior desse texto foi tentar mostrar como a heterogeneidade regional advinda da formação do Estado Nacional brasileiro forjou, nas unidades federadas em questão, republicanismos diferentes entre si, mas parecidos no caráter conservador e elitista, marca registrada da política brasileira, em todos quadrantes geográficos. 